\title{
The Effects of Cognitive Training for Elderly: Results from My Mind Project
}

\author{
Cinzia Giuli, Roberta Papa, Fabrizia Lattanzio, ${ }^{3}$ and Demetrio Postacchini ${ }^{1}$
}

\begin{abstract}
Cognitive decline and dementia represent very important public health problems that impact the ability to maintain social function and independent living. The aim of this study was to investigate the effects of a nonpharmacological intervention consisting of comprehensive cognitive training in elderly people having one of three different cognitive statuses. In all, 321 elderly people with a diagnoses of mild-moderate Alzheimer's disease (AD), with mild cognitive impairment (MCI) and without cognitive decline were randomly assigned to two groups: experimental group (EG, who underwent intervention) and control group $(\mathrm{CG})$, according to a prospective randomized intervention study. In the three groups, immediately after the end of the intervention, we observed a significant effect on some cognitive and noncognitive outcomes in the EGs. At the end of the intervention, we found an intermediate intervention effect on the Alzheimer's Disease Assessment Scale (ADAS) score of subjects with AD, as well as on functional status, as measured by using the Instrumental Activities of Daily Living scale. A significant intervention effect was also observed on enhancement of auditory verbal short-term memory and subjective memory complaints of subjects with MCI. The group of subjects without cognitive decline obtained a significant intervention effect on subjective complaints outcomes. The obtained results demonstrated that participation in the intervention could improve performance with respect to specific cognitive functions and psychological statuses. The role of healthy lifestyle programs, such as the use of comprehensive interventions, has been shown to be efficient for enhancing memory and other abilities in aged individuals with and without cognitive decline.
\end{abstract}

Keywords: multi-component cognitive training, Alzheimer's disease, mild cognitive impairment, comprehensive intervention, elderly

\section{Introduction}

A GING IS OFTEN associated with specific changes in cognitive functions, including a decline in attention processes, memory, and visuospatial and executive abilities. ${ }^{1}$ In particular, some studies found that in older people with cognitive decline, such as mild cognitive impairment (MCI), impairment in measures of acquisition, delayed recall, associative memory, face-name pairings, naming, visuospatial memory tasks, and attention deficits strongly predicted conversion to Alzheimer's disease (AD).,3

Nevertheless, aging, per se, is not inevitably linked to cognitive decline. Scientific literature on aging reported that it is possible to regain some lost cognitive functions, in particular in elderly subjects with cognitive decline, such as
MCI and dementia. ${ }^{4}$ Therefore, some authors posited that knowledge of normal and pathological changes in cognition of elderly people is very important for identifying interventions to optimize cognition in aging. ${ }^{5}$ Considering that elderly people have a high risk of serious cognitive diseases, identification of strategies and possible treatments for preventing cognitive decline, as well as the progression from mild cognitive decline to dementia, is necessary. ${ }^{6}$

The role of nonpharmacological strategies to slow or prevent the conversion from MCI to dementia is very important for reducing the use and costs of drugs and hospitalization for individuals with dementia. ${ }^{7}$ Since it is predicted that the incidence of dementia and AD will significantly increase in the future, this phenomenon will have an important impact on the healthcare system worldwide, in

\footnotetext{
${ }^{1}$ Unit of Geriatrics, Italian National Research Center on Aging, INRCA, Fermo, Italy.

${ }^{2}$ Centre of Socio-Economic Gerontological Research, Italian National Research Center on Aging, INRCA, Ancona, Italy.

${ }^{3}$ Scientific Direction, Italian National Research Center on Aging, INRCA, Ancona, Italy.
}

(C) Cinzia Giuli et al., 2016; Published by Mary Ann Liebert, Inc. This Open Access article is distributed under the terms of the Creative Commons Attribution Noncommercial License (http://creativecommons.org/licenses/by-nc/4.0/) which permits any noncommercial use, distribution, and reproduction in any medium, provided the original author(s) and the source are credited. 
particular relative to the medical, social, and economic costs for elderly people and their families. ${ }^{8}$

Cognitive training is considered an effective nonpharmacological intervention for many reasons. This therapy has commonly been used in recent years, because it has less risk and contraindication than do pharmacological strategies and it is preferred by elderly people. ${ }^{9}$

Interestingly, many studies have demonstrated the impact of cognitive rehabilitation and enhancement training on $\mathrm{AD}$, in addition to a positive effect on people with MCI and those without cognitive disease. ${ }^{10-12}$ Furthermore, findings have demonstrated that specific cognitive training in the elderly was associated with an improvement in neurophysiological and neuropsychological aspects. ${ }^{13,14}$ Thus, this shows a beneficial effect on stress, well-being, and mood status in both those with dementia and those without cognitive disease who undergo specific cognitive exercises. ${ }^{15}$

Despite the little evidence on the effectiveness in delaying difficulties in daily function, the ACTIVE study's randomized trial found that advanced cognitive training had a positive effect, showing less decline of instrumental activities of daily living (IADL), with consequent prevention and reduction of the risk of developing functional decline in older adults. ${ }^{16}$

Considering that the use of cognitive training courses is steadily increasing in different types of geriatric settings, there is a substantial need to promote both health and wellbeing programs in elderly people with and without cognitive decline. ${ }^{17}$ The idea is based, in accordance with this lifespan architecture, on a meta-theory of development regarding the orchestrated and adaptive interplay between three processes of behavioral regulation of functions in the elderly. ${ }^{18}$ Some authors have demonstrated the specific impact of personal resources and selection, optimization, and compensation life-management strategies on the subjective well-being and quality of life of the elderly. ${ }^{19}$ For this reason, diverse healthy lifestyle programs, such as cognitive and physical exercises, healthy eating, and stress reduction, have been shown to be extremely effective for enhancing memory and attention abilities of aged individuals with and without cognitive decline. ${ }^{20,21}$

In this context, some findings showed the importance of teaching memory training strategies and programs, taking into account the older adults' expectations of memory performance. $^{22}$ Often, a discrepancy between subjective memory complaints and actual memory performance in the elderly is observed. Indeed, the study of the role of subjective memory complaints, metamemory, and metacognition are also very important in the perception of cognitive functions because memory knowledge and objective memory performance can be effectively improved in old age through specific training. ${ }^{23}$ Recently, a study suggested that subjective memory complaints play a mediating role in the relationship between mood and cognitive functioning. ${ }^{24}$ Some authors have also demonstrated a beneficial impact of cognitive training on psychological and mood statuses in both healthy individuals and subjects with cognitive decline. ${ }^{6}$

Given this background, the effects of cognitive training have been investigated in three groups having different cognitive statuses. In this article, we present the results collected on behalf of My Mind Project: The effect of cognitive training for elderly, supported by the "Ricerca Finalizzata" (grant number 154/GR-2009-1584108) and funded by the Italian Ministry of Health and the Marche Region. In particular, the innovative contribution of this project regards a multidisciplinary approach to the study of cognitive disease in elderly people. Indeed, the multidimensional assessment includes an analysis of the interrelationships among cognitive, psychological, biochemical, nutritional, and social aspects. In this article, we analyzed only the immediate effects of cognitive training on some psychological aspects and cognitive statuses, but previous results showed a relationship between cognitive status and biochemical factors, as reported elsewhere. ${ }^{25}$ The multidisciplinary point of view is a very important process in aging research, because ageing is due to a complex interaction of genetic, epigenetic, and environmental factors. This evidence could support the hypothesis that elderly people who have better and more preserved cognitive functioning have healthier lifestyles compared with other groups. The influence of the role of biomarkers, lifestyle, and other psychological aspects in cognitive performance will be analyzed in future papers.

\section{Materials and Methods}

The Institutional Ethical Committee (code SC/12/301) approved this study. Sampling and administration procedures were carried out according to the national, ethical, and legal requirements for this type of study. Recruitment was performed through presentations to potential participants and their caregivers. The objectives of the study were described in detail and, if eligible, the subjects signed an informed consent regarding their anonymity, rights, and freedom to stop the phases of evaluation at any moment.

\section{Subjects and recruitment}

In all, 321 community-dwelling elderly subjects (age $\geq 65$ years) living in the Marche Region were recruited from the Evaluation of Alzheimer's unit (Geriatrics Operative Unit) at the INRCA Hospital in Fermo, Italy. The subjects were classified into three groups on the basis of their cognitive status: healthy elderly (HE), those with MCI, and subjects affected by mild-moderate AD.

The study design is a prospective, randomized intervention study for the assessment of the effects of cognitive training in three groups of elderly subjects having different cognitive statuses, using a multidisciplinary approach. Validated and widely used instruments were selected. Eligibility was determined after a complete medical and neuropsychological examination to assess inclusion/exclusion criteria. The inclusion criteria included: (1) being age 65 years or older, (2) having availability during the training and testing phases, and (3) the presence of a caregiver for subjects experiencing cognitive decline. The Local Ethical Committee included the latter criterion for subjects with cognitive decline, because having a caregiver present can ensure the participation of the subjects, inform staff involved in the intervention of clinical and pharmacological statuses of the patients, support subjects in cognitive stimulation homework assignments, ensure that the caregivers receive psychoeducation, and facilitate the teaching of strategies for use at home. Exclusion criteria included: (1) the presence of serious medical or psychiatric conditions and sensorimotor deficits that would prevent participation in training, (2) the presence of neurodegenerative disorders other than $\mathrm{AD}$, and (3) severe $\mathrm{AD}$. 
The status of healthy subjects was defined as the absence of relevant cognitive diseases. Diagnosis of MCI was carried out by using Petersen's criteria. ${ }^{26}$ At the same time, the functional neuroimaging techniques (such as CT or MRI), laboratory analysis procedures, and other medical examinations were required to differentiate $\mathrm{AD}$ from other possible causes. Diagnosis for possible or probable AD was carried out by using the DSM-IV or NINCDS-ADRDA criteria. $^{27}$

After enrolment in the study, the subjects were randomly assigned 1:1 to the experimental group (EG) or the control group (CG). Randomization was performed separately for each group (HE, MCI, AD) by using a computerized random number generator; a list of subjects' IDs and intervention groups was provided to the principal investigator.

The HE group was composed of 55 subjects included in EG and 56 in CG. MCI was composed of 54 subjects included in EG and 55 in CG. The AD group was divided into 51 subjects included in EG and 50 in CG. After the evaluation, each subject was involved in the intervention on the basis of the assigned group. The EG received the training intervention, which was carried out by experienced psychologists. For this study, only subjects that completed both the baseline and the first follow-up were considered $(n=292): 100 \mathrm{HE}$ subjects (47 included in EG and 53 in CG), 97 MCI subjects (48 included in EG and 49 in CG), and 95 AD subjects (48 included in EG and 47 in $\mathrm{CG}$ ).

\section{Intervention of comprehensive training}

The main aim of the intervention was to improve different cognitive functions to activate and motivate participants to improve their cognitive health behaviors by remaining cognitively active and compensating for deficits by using learned mnemonic strategies after training. In particular, an approach that combined cognitive training focusing on lifestyle changes with monitoring of psycho-social and functional statuses was used for each group. Thus, different comprehensive training methods were applied to the different groups of subjects on the basis of their cognitive status. Indeed, each group did not receive identical training, because each method used was adequate for the particular cognitive status.

In general, the intervention addressed not only cognitive enhancement or stimulation but also aspects such as education about healthy lifestyle strategies and nutrition to maintain cognitive reserves, engagement in leisure activities, and socialization. This intervention, which included restorative and compensatory approaches and advice for lifestyle and psychological support, was used for subjects with MCI and for those with mild-moderate $\mathrm{AD}$, taking an individualized approach to identify individual goals and practice strategies. On the other hand, healthy subjects received a group session approach. Intervention for $\mathrm{HE}$ focused on, in particular, enhancing working memory and learning processes, whereas those for MCI and AD subjects primarily focused on learning strategies of categorization, clustering, attention, and visuospatial processes.

The cognitive enhancing training for HE consisted of 10 sessions of 90 minutes each in groups of about 10 subjects, once a week. Training in memory strategies involved learning and practicing strategies such as mnemonics and visual imagery. The LAB-I methodology ${ }^{28}$ was used. The domains addressed working memory and learning processes, using a metacognitive approach. Participants were taught mnemonic strategies for remembering word lists, sequences of items, and the creation of stories. For example, participants were instructed on how to organize word lists into meaningful categories and to form visual images and mental associations for recalling words and texts. Another important aim of this enhancement training focused on maximizing social participation. In addition, the role of metamemory and metacognition was investigated. Participants were also asked to perform cognitive and metacognitive at-home exercises each day, which were delivered to all participants. The participants were required to do the homework before the subsequent session, according to LAB-I methodology. ${ }^{28}$

The MCI group received 10 individual sessions of 45 minutes, once a week. The training included learning strategies for orientation, memory, categorization, and clustering. Since MCI subjects often present some level of anxiety, stress, and/or depression due to their consciousness of cognitive decline, the effect of subjective complaints and metamemory was evaluated because of the important role in the perception of cognitive decline. Some practical and compensation strategies were taught, and aids and psychological support were provided for stress and mood disease management to improve performance and psycho-education about memory loss and memory tasks related to cognitive activities of everyday life. Advice and education on healthy lifestyles were also provided. Participants were asked to perform cognitive at-home exercises each day, which were delivered to all participants. Homework was assigned at the close of each class and was reviewed during the next class. The role of the caregiver was very important to help and support the patients in performing at-home exercises.

The AD group received 10 individual sessions of 45 minutes each, once a week. They received a stimulation training program addressing cognitive functions, and in particular, the empowerment of attention functions, orientation, planning of activities of daily living, and episodic and prospective memory. As subjects with MCI, participants were also asked to perform homework exercises each day with the help and support of a caregiver.

Another aim of the intervention was to decrease functional disability, maximize engagement in daily living and healthy lifestyle activities, and support patients with psychological disorders and their caregivers. Members of the $\mathrm{CG}$ for each situation did not receive the intervention, but they instead receive a general psychoeducational approach, including some suggestions and simple strategies on how to improve memory and health status. This strategy is usually used during visits for patients who are being examined at the Evaluation of Alzheimer's unit at the INRCA Hospital in Fermo and for patients who do not undergo cognitive intervention. This approach is considered appropriate for attenuating the intervention effects and for minimizing the cognitive engagement of subjects, as also indicated in another study. ${ }^{29}$ Members of the CG were tested at baseline and during three follow-up phases by using the neuropsychological and clinical assessments at the same time as the EG. All study procedures for the CG were identical to the EG except that there was no intervention. 
Table 1. Neuropsychological Assessment at Baseline and Three Follow-Up Phases by Group

\begin{tabular}{|c|c|c|c|c|}
\hline \multirow[b]{2}{*}{ Instrument } & \multicolumn{3}{|c|}{ Groups } & \multirow[b]{2}{*}{ Description } \\
\hline & Healthy & $M C I$ & $A D$ & \\
\hline $\mathrm{MMSE}^{30}$ & $*$ & $*$ & * & $\begin{array}{l}\text { Assessment of global cognitive abilities } \\
\text { Score range: } 0-30\end{array}$ \\
\hline Supra-span of Corsi ${ }^{31}$ & N.A. & $*$ & $*$ & $\begin{array}{l}\text { Assessment of orientation and spatial attention } \\
\text { Cut-off point: } 3.50\end{array}$ \\
\hline Backward and forward $\operatorname{span}^{32}$ & $*$ & $*$ & $*$ & $\begin{array}{l}\text { Assessment of span of immediate verbal recall and working } \\
\text { memory } \\
\text { Cut-off point: } 3.75\end{array}$ \\
\hline List of words ${ }^{33}$ & $*$ & N.A. & N.A. & $\begin{array}{l}\text { Assessment of memory and learning processes of a list of words } \\
\text { Score range: } 0-12\end{array}$ \\
\hline Prose memory test ${ }^{34}$ & N.A. & $*$ & $*$ & $\begin{array}{l}\text { Assessment of the long-term memory on immediate recall } \\
\text { Score range: } 0-16 \\
\text { Cut-off point }=4.75\end{array}$ \\
\hline Word pairing learning test ${ }^{35}$ & N.A. & $*$ & $*$ & $\begin{array}{l}\text { Assessment of verbal memory and learning of word pairs } \\
\text { Score range: } 0-22.5 \\
\text { Cut-off point: } 8.73\end{array}$ \\
\hline Attentive matrices ${ }^{34}$ & $*$ & $*$ & $*$ & $\begin{array}{l}\text { Assessment of selective and the sustained attention } \\
\text { Score range: } 0-60 \\
\text { Cut-off point: } 31\end{array}$ \\
\hline Semantic word fluency test ${ }^{36}$ & N.A. & $*$ & $*$ & $\begin{array}{l}\text { Assessment of lexical access and semantic fluency. Subjects are } \\
\text { required to say words for a specific category (for example, } \\
\text { fruits, animals) } \\
\text { Cut-off point: } 25\end{array}$ \\
\hline Phonemic word fluency test ${ }^{36}$ & $*$ & $*$ & $*$ & $\begin{array}{l}\text { Assessment of lexical access and phonemic fluency. Subjects are } \\
\text { required to produce words beginning with a particular letter of } \\
\text { the alphabet. } \\
\text { Cut-off point: } 17.35\end{array}$ \\
\hline $\mathrm{ADAS}^{37}$ & N.A. & N.A. & $*$ & $\begin{array}{l}\text { Assessment of cognitive decline in dementia. It consists of } 12 \\
\text { sub-tests for evaluation of memory, orientation, language, praxis, } \\
\text { attention, and concentration. They are divided as following: word } \\
\text { recall task, naming objects and fingers, commands, constructional } \\
\text { praxis, ideational praxis, orientation, word recognition task, } \\
\text { language, comprehension of spoken language, word-finding } \\
\text { difficulty, and remembering test instructions. } \\
\text { Score range: } 0-70\end{array}$ \\
\hline Clinical Dementia Rating Scale ${ }^{38}$ & N.A. & $*$ & $*$ & $\begin{array}{l}\text { Assessment of overall dementia severity } \\
\text { Score range: } 0-5\end{array}$ \\
\hline GDS $-30^{39}$ & $*$ & $*$ & $*$ & $\begin{array}{l}\text { Assessment of mood status and depression } \\
\text { Score range: } 0-30 \\
\text { Cut-off point: } 10\end{array}$ \\
\hline $\mathrm{PSS}^{40}$ & $*$ & $*$ & N.A. & $\begin{array}{l}\text { Assessment of perceived psychological stress. It comprises } \\
14 \text { items and its questions asked about feelings and thoughts } \\
\text { during the last month. } \\
\text { Score range: } 0-56 \\
\text { Scores above mean indicated high stress level. }\end{array}$ \\
\hline $\mathrm{ADL}^{41}$ & $*$ & $*$ & $*$ & $\begin{array}{l}\text { Assessment of functional status of basic activities of daily living } \\
\text { Score range: } 0-6\end{array}$ \\
\hline $\mathrm{IADL}^{42}$ & $*$ & $*$ & $*$ & $\begin{array}{l}\text { Assessment of functional status of IADL } \\
\text { Score range: } 0-8\end{array}$ \\
\hline $\mathrm{MAC}-\mathrm{Q}^{43}$ & $*$ & $*$ & N.A. & $\begin{array}{l}\text { Assessment of daily activities and overall memory functioning } \\
\text { comparing the present moment with the past. It was designed } \\
\text { to assess subjective memory complaints. } \\
\text { Score range: } 7-35 \\
\text { Cut-off point: } 25\end{array}$ \\
\hline Questionnaire of confidence ${ }^{33}$ & $*$ & N.A. & N.A. & $\begin{array}{l}\text { Assessment of subjective confidence in own cognition and } \\
\text { memory } \\
\text { Score range: } 5-15\end{array}$ \\
\hline
\end{tabular}

A decrease of the scores of ADAS, perceived stress scale, and MAC-Q scales represent an improvement of performance in the relevant area of assessment.

*Instrument administered to this group.

AD, Alzheimer's disease; ADAS, Alzheimer's Disease Assessment Scale; GDS, Geriatric Depression Scale; IADL, Instrumental Activities of Daily Living; MAC-Q, Memory Assessment Complain Questionnaire; MCI, mild cognitive impairment; MMSE, Mini Mental State Examination; N.A., not applicable (not administered to this group); PSS, Perceived Stress Scale. 


\section{Neuropsychological assessment before and after intervention}

The neuropsychological test battery comprised instruments that are sensitive to age-related cognitive decline and have good reliability and validity (as reported in Table 1). All measures assessed using these instruments were considered targets for the evaluation of intervention effects, in accordance with the main and secondary outcomes of the projects. The instruments were chosen in accordance with previous studies for assessment of distinctive domains. ${ }^{12,29}$

\section{Statistical analysis}

The analysis was performed by using SPSS 16 software (SPSS, Inc., Chicago, IL). A descriptive analysis was carried out to describe the main characteristics of the sample. Categorical variables were compared by using a chi-square test, and for continuous variables, a $t$-test for independent samples was used.

For all groups (HE, MCI, AD) and for each intervention group (EG and CG), a comparison of neuropsychological assessments both before and after the intervention was performed by using a paired $t$-test. Moreover, a 2 (training groups: EG and CG) $\times 2$ (time-points: baseline and followup) repeated-measures ANOVA for examining the training effect on each outcome variable was carried out separately for $\mathrm{HE}, \mathrm{MCI}$, and $\mathrm{AD}$. In particular, outcome measures at both baseline and follow-up were used as within factors, whereas the intervention group was used as the between factor. All models were adjusted for age and years of education. For each model, partial eta squared is presented as the effect size. Significance was set at $p<0.05$.

\section{Results}

The general and socio-demographic characteristics of the subjects are reported in Table 2. The majority of subjects were women, and they were either married or cohabiting with their partner. The cognitive outcomes of each group with different cognitive statuses are not compared across them, but the results of each group are compared between the EG and the CG.

\section{Effects of intervention on cognitive outcomes}

Tables 3-5 show the baseline and follow-up assessments separately for each group. There are some differences between the experimental and CGs. In particular, for HE, a significant increase of "auditory verbal short-term memory," as measured by using "forward verbal span," was observed in EG $(p<0.001)$. In addition, the number of remembered words from a list was observed in the EG $(p=$ 0.001), whereas no difference occurred for CG. As reported in Table 3, the repeated-measures ANOVA showed a small effect size (0.079 and 0.070 , respectively) of the intervention on memory processes $(p<0.05)$.

As shown in Table 4, MCI presents significant intervention effects in many cognitive outcomes, such as "auditory verbal short-term memory," as measured by using the "backward verbal span" $\left(p<0.001 ; \eta_{\text {partial }}{ }^{2}=0.120\right)$, on "memory of prose" $\left(p<0.01 ; \eta_{\text {partial }}{ }^{2}=0.088\right)$, "visuospatial short-term memory," as measured by using the "supra-span of corsi", $\left(p<0.01 ; \eta_{\text {partial }}{ }^{2}=0.094\right)$, "learning and memory of word pairs" $\left(p<0.01 ; \eta_{\text {partial }}{ }^{2}=0.062\right)$, and "selective attentive processes" $\left(p<0.001 ; \eta_{\text {partial }}{ }^{2}=0.194\right)$.

In the $\mathrm{AD}$ group, EG showed improvements on "selective attentive processes" $(p=0.036)$, "auditory verbal shortterm memory," as measured by using "backward and forward verbal span" ( $p=0.017$ and $p=0.004$, respectively), "word pairing learning" ( $p=0.044)$, and total score of the Alzheimer's Disease Assessment Scale (ADAS) $(p<0.001)$. Moreover, small-to-intermediate intervention effects were observed, as shown in Table 5. The sub-scales of the ADAS (data not shown), such as "word recall task" $(p=0.005)$, "naming objects and fingers" ( $p=0.008)$, and "word recognition task" $(p<0.001)$, significantly improved in EG after the intervention compared with the CG.

Table 2. Sample Characteristics by Group and Intervention

\begin{tabular}{|c|c|c|c|c|c|c|c|c|c|c|}
\hline & \multicolumn{9}{|c|}{ Groups } & \multirow[b]{3}{*}{$\mathrm{p}$-Value } \\
\hline & \multicolumn{3}{|c|}{ Healthy $(\mathrm{n}=100)$} & \multicolumn{3}{|c|}{$M C I(\mathrm{n}=97)$} & \multicolumn{3}{|c|}{$A D(\mathrm{n}=95)$} & \\
\hline & $E G(\mathrm{n}=47)$ & $C G(\mathrm{n}=53)$ & Sign. $^{\mathrm{a}}$ & $E G(\mathrm{n}=48)$ & $C G(\mathrm{n}=49)$ & Sign. $^{\mathrm{a}}$ & $E G(\mathrm{n}=48)$ & $C G(\mathrm{n}=47)$ & Sign. $^{\mathrm{a}}$ & \\
\hline Age (years) & $72.7(5.2)$ & $72.2(6.6)$ & n.s. & $76.0(6.3)$ & $76.5(5.7)$ & n.s. & $76.5(4.3)$ & $78.7(5.9)$ & $*$ & $<0.001$ \\
\hline Gender & & & n.s. & & & n.s. & & & n.s. & 0.020 \\
\hline Male & 17 & 23 & & 35 & 39 & & 40 & 28 & & \\
\hline Female & 83 & 77 & & 65 & 61 & & 60 & 72 & & \\
\hline Education (years) & $11.1(4.5)$ & $8.6(4.4)$ & $* *$ & $6.7(3.8)$ & $5.3(3.0)$ & $*$ & $5.9(4.1)$ & $4.5(2.3)$ & $*$ & $<0.001$ \\
\hline Marital status & & & n.s. & & & n.s. & & & n.s. & 0.010 \\
\hline Married/cohabiting & 47 & 58 & & 62 & 76 & & 73 & 55 & & \\
\hline Widowed & 40 & 34 & & 38 & 22 & & 25 & 43 & & \\
\hline Other & 13 & 8 & & 0 & 2 & & 2 & 2 & & \\
\hline MMSE & $27.9(1.1)$ & $28.0(1.1)$ & n.s. & $25.7(1.8)$ & $25.8(1.9)$ & n.s. & $20.2(3.7)$ & $20.3(3.5)$ & n.s. & $<0.001$ \\
\hline GDS & $8.9(4.7)$ & $6.6(5.0)$ & $*$ & $8.6(4.8)$ & $8.8(4.0)$ & n.s. & $8.4(6.2)$ & $8.1(5.3)$ & n.s. & n.s. \\
\hline $\begin{array}{l}\text { Number of diseases } \\
\text { (range } 0-11)\end{array}$ & $3.7(1.7)$ & $3.2(2.0)$ & n.s. & $3.3(1.6)$ & $3.6(1.7)$ & n.s. & $4.4(1.7)$ & $4.4(1.7)$ & n.s. & $<0.001$ \\
\hline BADL & $5.9(0.3)$ & $5.9(0.3)$ & n.s. & $5.9(0.3)$ & $5.8(0.4)$ & n.s. & $5.1(1.4)$ & $5.1(1.0)$ & n.s. & $<0.001$ \\
\hline IADL & $7.9(0.3)$ & $7.9(0.4)$ & n.s. & $6.9(1.4)$ & $6.9(1.5)$ & n.s. & $3.3(2.3)$ & $3.4(1.8)$ & n.s. & $<0.001$ \\
\hline
\end{tabular}

Data presented as percentages and mean (SD).

${ }^{\mathrm{a}} \mathrm{Chi}$-square for frequencies or $t$-test for means, comparison of EG and CG within each group.

${ }^{\mathrm{b}} \mathrm{Chi}$-square for frequencies or $t$-test for means, comparison of groups (healthy, MCI, AD).

$* p$-value $<0.05 ; * *<0.01$.

CG, control group; EG, experimental group; n.s., not significant. 
Table 3. Assessment At Baseline and After the Intervention in the Group of Healthy Elderly

\begin{tabular}{|c|c|c|c|c|c|c|c|c|}
\hline & \multicolumn{3}{|c|}{$E G$} & \multicolumn{3}{|c|}{$C G$} & \multicolumn{2}{|c|}{ Group $\times$ time interaction } \\
\hline & Baseline & Follow-up & $\mathrm{p}-$ Value $^{\mathrm{a}}$ & Baseline & Follow-up & $\mathrm{p}-$ Value $^{\mathrm{a}}$ & $\mathrm{F}^{\mathrm{b}}$ & Effect size \\
\hline Forward verbal span & $4.39(1)$ & $5.08(1)$ & $<0.001$ & $4.79(1)$ & $4.82(0.9)$ & 0.814 & $7.68 * *$ & 0.079 \\
\hline Backward verbal span & $3.36(1)$ & $3.6(1.2)$ & 0.070 & $3.25(1.1)$ & $3.08(1.2)$ & 0.316 & 2.97 & 0.033 \\
\hline List of words & $4.35(1.3)$ & $5.15(1.5)$ & 0.001 & $4.71(1.6)$ & $4.71(1.6)$ & 1.00 & $6.66 * *$ & 0.070 \\
\hline MAC-Q & $24.77(3.6)$ & $19.21(4.1)$ & $<\mathbf{0 . 0 0 1}$ & $24.04(3.3)$ & $24.45(3.3)$ & 0.207 & $53.99 * * *$ & 0.386 \\
\hline Confidence & $8.77(1.6)$ & $10.09(1.6)$ & $<0.001$ & $9.26(1.6)$ & 8.9 (1.9) & 0.063 & $14.52 * * *$ & 0.146 \\
\hline GDS & $9.49(5)$ & $9.09(4.6)$ & 0.471 & $6.47(5.1)$ & $7.94(5.3)$ & $<\mathbf{0 . 0 0 1}$ & $5.37 *$ & 0.059 \\
\hline PSS & $25.07(5.9)$ & $23.19(5.9)$ & 0.019 & $22.12(6.3)$ & $23.63(6)$ & 0.050 & $7.18 * *$ & 0.077 \\
\hline ADL & $5.93(0.3)$ & $5.91(0.3)$ & 0.323 & $5.86(0.4)$ & $5.86(0.4)$ & 1.00 & 2.14 & 0.024 \\
\hline IADL & $8(0)$ & $8(0)$ & 1.00 & $7.84(0.7)$ & $7.82(0.7)$ & 0.322 & 0.55 & 0.006 \\
\hline
\end{tabular}

Data presented as mean (SD).

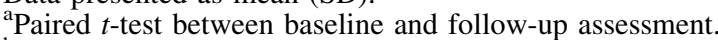

${ }^{\mathrm{b}}$ Repeated-measures ANOVA testing interaction of intervention (EG vs. CG) per time (baseline vs. follow-up) for each outcome; adjusted for age and years of education. $F$ test and $p$-value $(*<0.05 ; * *<0.01 ; * * *<0.001)$; effect size is partial eta squared $\left(\eta_{\text {partial }}{ }^{2}\right)$ for group $\times$ time.

Significant values are in bold.

\section{Effects of intervention on subjective memory complaint and metamemory}

As explained, the analysis of subjective memory complaints and metamemory could be important for better management of related psychological aspects, with a consequent positive effect on well-being, mood status, and stress level. The role of these aspects was investigated by using the Memory Assessment Complain Questionnaire (MAC-Q) for the MCI and HE groups. As shown in Tables 3 and 4, in the EGs of HE and MCI subjects ( $p<0.001$ for both groups), a significant decrease of the MAC-Q score was observed, representing an improvement in the perception of subjective memory. Moreover, the repeated-measures ANOVA showed a significant effect with a moderate intervention effect size $\left(\eta_{\text {partial }}{ }^{2}=0.386\right.$ and $\eta_{\text {partial }}{ }^{2}=0.257$ for $\mathrm{HE}$ and MCI, respectively). Moreover, for $\mathrm{HE}$, an increase of "confidence of own memory" was observed $(p<0.001)$ only in EG after the training, with a moderate effect size $\left(\eta_{\text {partial }}{ }^{2}=0.146\right)$.

\section{Effects of intervention on functional status}

In the $\mathrm{CG}$ of $\mathrm{MCI}$, a significant decrease of IADL $(p=0.004)$ was observed after training, with a small intervention effect detected. The same results were obtained in the $\mathrm{CG}$ of the AD group for the ADL $(p=0.024)$ and IADL scales $(p=0.002)$. In the IADL scale, we observed an intermediate effect $\left(\eta_{\text {partial }}{ }^{2}=0.163\right)$. In contrast, the EG of AD demonstrated a significant increase of IADL score at the posttest $(p=0.009)$.

\section{Effects of intervention on mood status and perceived stress}

The intervention had no significant effects on these outcomes, although some results were observed. Indeed, the $\mathrm{CG}$ of HE showed a significant increase of Geriatric Depression Scale (GDS) $(p<0.001)$ and the Perceived Stress Scale (PSS) scores $(p=0.050)$, indicating a worsening of

Table 4. Assessment at Baseline and After the Intervention in the Group of Mild Cognitive Impairment

\begin{tabular}{|c|c|c|c|c|c|c|c|c|}
\hline & \multicolumn{3}{|c|}{$E G$} & \multicolumn{3}{|c|}{$C G$} & \multicolumn{2}{|c|}{ Group $\times$ time interaction } \\
\hline & Baseline & Follow-up & $\mathrm{p}-$ Value $^{\mathrm{a}}$ & Baseline & Follow-up & $\mathrm{p}-$ Value $^{\mathrm{a}}$ & $\mathrm{F}^{\mathrm{b}}$ & Effect size \\
\hline Forward verbal span & $4.52(0.8)$ & $4.68(0.9)$ & 0.211 & $4.69(0.8)$ & $4.5(0.8)$ & 0.095 & $3.96 *$ & 0.042 \\
\hline Backward verbal span & $2.76(0.9)$ & $3.04(0.9)$ & 0.051 & $2.75(0.8)$ & $2.40(0.7)$ & 0.004 & $12.31 * * *$ & 0.120 \\
\hline GDS & $10.41(6.2)$ & $9.78(6)$ & 0.286 & $9.17(5)$ & $10.38(5.1)$ & 0.093 & $4.97 *$ & 0.052 \\
\hline MAC-Q & $27.37(3.7)$ & $23.43(4.5)$ & $<0.001$ & $25.69(3.1)$ & $26.44(3.8)$ & 0.099 & 31.10*** & 0.257 \\
\hline PSS & $19.7(7.7)$ & $18.41(8.1)$ & 0.311 & $18.73(7.5)$ & $19.96(8.8)$ & 0.313 & 2.52 & 0.027 \\
\hline MMSE & $25.85(1.9)$ & $25.62(2.5)$ & 0.501 & $25.85(2.3$ & $25.43(3.2$ & 0.178 & 0.02 & 0.000 \\
\hline ADL & $5.83(0.4)$ & $5.85(0.4)$ & 0.660 & $5.83(0.4)$ & $5.75(0.4)$ & 0.103 & 1.07 & 0.012 \\
\hline IADL & $7.43(0.9)$ & $7.43(0.9)$ & 1.00 & $7.5(0.8)$ & $7.17(1.3)$ & 0.004 & $5.55 *$ & 0.058 \\
\hline Prose memory test & $7.05(3.8)$ & $8.78(3.9)$ & 0.004 & $7.2(4.5)$ & $6.56(4.2)$ & 0.197 & $8.57 * *$ & 0.088 \\
\hline Word pairing learning test & $8.45(3.6)$ & $9.6(4.7)$ & 0.018 & $6.69(3.2)$ & $6.41(2.9)$ & 0.478 & $6.02 *$ & 0.062 \\
\hline Supra-span of Corsi & $4.84(0.8)$ & $5.11(0.8)$ & 0.040 & $5.04(0.7)$ & $4.8(0.9)$ & 0.035 & $9.18 * *$ & 0.094 \\
\hline Semantic word fluency test & $1.87(1.3)$ & $2(1.5)$ & 0.323 & $2.19(1.3)$ & $2.19(1.3)$ & 1.00 & 0.52 & 0.006 \\
\hline Phonemic word fluency test & $29.23(8.2)$ & $30.85(8.6)$ & 0.083 & $24.39(7.9)$ & $23.85(5.9)$ & 0.477 & 3.65 & 0.042 \\
\hline Attentive matrices & $38.61(10.1)$ & $42.15(9.9)$ & $<\mathbf{0 . 0 0 1}$ & $40.75(9.6)$ & $39.16(10)$ & 0.034 & 21.47*** & 0.194 \\
\hline
\end{tabular}

Data presented as mean (SD).

${ }^{\text {a}}$ Paired $t$-test between baseline and follow-up assessment.

${ }^{\mathrm{b}}$ Repeated-measures ANOVA testing interaction of intervention (EG vs. CG) per time (baseline vs. follow-up) for each outcome; adjusted for age and years of education. $F$ test and $p$-value $(*<0.05 ; * *<0.01 ; * * *<0.001)$; effect size is partial eta squared $\left(\eta_{\text {partial }}{ }^{2}\right)$ for group $\times$ time. Significant values are in bold. 
Table 5. Assessment at Baseline and After the Intervention in the Group of Alzheimer's Disease

\begin{tabular}{|c|c|c|c|c|c|c|c|c|}
\hline & \multicolumn{3}{|c|}{$E G$} & \multicolumn{3}{|c|}{$C G$} & \multicolumn{2}{|c|}{ Group $\times$ time interaction } \\
\hline & Baseline & Follow-up & $\mathrm{p}-$ Value $^{\mathrm{a}}$ & Baseline & Follow-up & $\mathrm{p}-$ Value $^{\mathrm{a}}$ & $F^{b}$ & Effect size \\
\hline Forward verbal span & $3.9(1)$ & $4.23(1)$ & 0.004 & $4.36(0.9)$ & $4.19(1.1)$ & 0.232 & $7.69 * *$ & 0.083 \\
\hline Backward verbal span & $1.91(0.9)$ & $2.23(1.1)$ & 0.017 & $2.11(1.0)$ & $1.89(1.0)$ & 0.168 & $9.36 * *$ & 0.099 \\
\hline GDS & $9.78(7)$ & $9.96(6.9)$ & 0.745 & $8.65(5.8)$ & $9.89(6.1)$ & 0.031 & 1.69 & 0.020 \\
\hline MMSE & $20.48(4.2)$ & $20.5(4.5)$ & 0.976 & $20.11(4.2)$ & $20.14(4)$ & 0.922 & 0.02 & 0.000 \\
\hline ADL & $5.39(0.9)$ & $5.43(0.8)$ & 0.486 & $4.98(1.2)$ & $4.87(1.2)$ & 0.024 & 4.81* & 0.054 \\
\hline IADL & $3.37(1.9)$ & $3.63(1.9)$ & 0.009 & $3.37(2)$ & $3.13(2)$ & 0.002 & $16.53 * * *$ & 0.163 \\
\hline Prose memory test & $4.71(3.8)$ & $5.34(3.6)$ & 0.220 & $3.49(3.4)$ & $3.61(3.2)$ & 0.722 & 1.20 & 0.014 \\
\hline Word pairinglearning test & $4.1(2.4)$ & $4.75(2.9)$ & 0.044 & $4.25(2.7)$ & $4.08(2.8)$ & 0.617 & 3.34 & 0.038 \\
\hline Supra-span of Corsi & $3.99(1.3)$ & $4.03(1.1)$ & 0.772 & $4.01(1.2)$ & $4(1.3)$ & 0.931 & 0.01 & 0.000 \\
\hline Semantic word fluency test & $0.87(1.2)$ & $1.02(1.1)$ & 0.181 & $1(1.1)$ & $0.83(1)$ & 0.044 & $4.75 *$ & 0.053 \\
\hline Attentive matrices & $26.4(8.6)$ & $28.35(10.1)$ & $\mathbf{0 . 0 3 6}$ & $29.76(9)$ & $29.15(8.6)$ & 0.175 & $12.62 * * *$ & 0.136 \\
\hline ADAS & $20.6(9.3)$ & $17.3(9.2)$ & $<\mathbf{0 . 0 0 1}$ & $19.6(9.6)$ & $19.59(9.2)$ & 0.959 & $10.66 * *$ & 0.111 \\
\hline
\end{tabular}

Data presented as mean (SD).

${ }^{a}$ Paired $t$-test between baseline and follow-up assessment.

${ }^{\mathrm{b}}$ Repeated-measures ANOVA testing interaction of intervention (EG vs. CG) per time (baseline vs. follow-up) for each outcome; adjusted for age and years of education. $F$ test and $p$-value $(*<0.05 ; * *<0.01 ; * * *<0.001)$; effect size is partial eta squared $\left(\eta_{\text {partial }}{ }^{2}\right)$ for group $\times$ time. Significant values are in bold.

mood status and perceived stress; whereas this result was not observed in EG. Instead, an opposite result was observed for $\mathrm{EG}(p=0.019)$. In the $\mathrm{CG}$ of the $\mathrm{AD}$, we observed a significant increase of GDS score $(p=0.031)$ near the cutoff score of depression (i.e., a score of 10). This result was not observed in the EG.

\section{Discussion}

This study was designed to investigate the effects of a comprehensive cognitive intervention on different groups of elderly people. The results of our analysis showed more positive immediate effects on many outcomes in the EGs compared with those in the CGs. These results support the assumption that cognitive training could be an effective intervention for elderly people with early stage AD or MCI, as well as for those without relevant cognitive deficits. Indeed, many studies indicated the efficacy of this intervention observed in elderly people with and without cognitive decline, as reported in some reviews of the literature on this topic. $^{12,44}$ Nevertheless, some authors stated that there is a lack of theoretical rehabilitation models to guide assessment of this intervention, and for this reason, it is important to take into account many aspects in the rehabilitation of elderly people with cognitive deficits, in particular those with MCI. ${ }^{12}$ Indeed, the use of comprehensive multi-modal cognitive training that includes a restorative and compensatory approach, in addition to advice for lifestyle intervention and psychological support for psychological disorders, is indicated. ${ }^{45}$

The main scope of "My Mind Project" was to demonstrate that comprehensive cognitive training could have a positive effect with respect to this intervention for elderly people with different cognitive statuses, and the strength of the multidisciplinary approach allows for analyzing the role of many factors in the management of rehabilitation and the enhancement of cognitive functions in the elderly.

First, interesting results were observed in the areas of subjective memory complaints, metamemory, "confidence of own memory," and self-efficacy of subjects without signifi- cant cognitive deficits and in subjects with MCI. Often, elderly people complain about difficulties in carrying out daily living activities due to their perception of mnemonic deficits, although they do not present an objective and documented memory decline. As evidenced by some authors, these subjects have a higher risk of developing dementia and $\mathrm{AD}{ }^{46}$ For this reason, it is very important to identify this group of subjects who may be vulnerable to dementia.

The literature offers evidence that the absence of complaints and the subjective perception of cognitive deficits could be considered successful aging indicators. ${ }^{47}$ In this context, memory training and educational interventions seem useful for elevating self-efficacy and for promoting active transfer of strategies to maintain independence and improve health-related quality of life in the elderly. ${ }^{48}$ Particular attention should be paid to subjects with MCI, who may recognize their own cognitive decline and, consequently, develop mood disorders and other afflictions, as well as demonstrate reduced self-esteem and affliction due to fear of developing dementia. ${ }^{49}$ Surely, in these subjects, cognitive training should be conducted with full attention to the mental state of the individual, because the risk exists of aggravating their awareness of memory decline, exacerbating the sense of self-efficacy with consequent worsening of quality of life. ${ }^{48}$

Our findings demonstrate improvements in cognitive performance and psychological status, which are observed immediately after the cognitive intervention. Indeed, in subjects without cognitive deficits who underwent cognitive training, an increase of performance, such as memory and learning processes, was observed, which was in line with the results presented in a very recent paper. ${ }^{17}$ On the contrary, a review showed that in subjects with $\mathrm{AD}$, the intervention effect was observed only in global cognitive functions, as assessed by using the Mini Mental State Examination (MMSE), but it was not observed in other cognitive domains. ${ }^{29}$ Moreover, a reduction in the level of perceived psychological stress was observed. This confirms that, as also observed by many authors whose results are shown in a systematic review, there is a beneficial impact on psychological status in healthy subjects after cognitive training. ${ }^{50}$ 
In our sample, the MCI EG obtained some interesting results illustrating improvement in different memory and learning cognitive tests, as well as in selective attentive processes and verbal fluency, when compared with the CG. This result suggests that the intervention could have an important impact on cognitive performances of subjects with mild cognitive decline, and that this intervention is necessary for elderly people with a high risk of conversion to dementia, as other authors have also concluded. ${ }^{51}$ The latter study evidenced that cognitive exercise training in healthy older individuals has a protective effect on longitudinal neuropsychological performance.

In the EG of subjects with $\mathrm{AD}$, there was some improvement in cognitive functions, such as memory, attention, and degree of dementia. The mood status was not worse in the EG, contrary to results observed in the CG. Furthermore, there was some beneficial impact on mood status in subjects with cognitive deficits after cognitive training, as also observed in other studies. ${ }^{9}$

Interesting results were obtained for functional status in groups with cognitive decline (MCI and AD subjects). Indeed, the findings showed that in the CGs, the score of the IADL scale decreased, with a large intervention effect in subjects with AD and an intermediate effect in subjects with MCI. Surely, many variables could be related to this effect and assessment of this relationship is complex. Nevertheless, it is possible to identify some possible explanations, including that the intervention could produce changes in behavior and social interactions, supporting engagement in functional activities, as Rebok and other authors found. ${ }^{16}$ Moreover, we believe that the improvement in one's positive psychological characteristics, awareness, and confidence in his or her abilities could have a positive effect on the planning and mastery of daily living activities. The LASA study hypothesized that the sense of control while persevering in the face of difficulties with daily living activities and setbacks play a role in delaying the onset of functional disabilities. This is particularly true in subjects with higher levels of investment in one's independence, since they are more likely to utilize strategies. ${ }^{52}$

Considering that other characteristics, such as educational level, gender, social support, and psychological aspects, could have an influence on this relationship, further analysis will be conducted to identify the relationship between cognitive performances and other factors. A longitudinal study will be useful for identifying the effect of comprehensive cognitive training over 6 months and 2 years at the end of the intervention (phases of follow-up 2 and 3 ) on the health status and functional aspects of all recruited subjects.

Another aim of the proposed future research is the specific analysis of MCI subjects who converted to dementia. In addition, their characteristics will be analyzed. Moreover, characteristics of subjects who are successful with cognitive training will be analyzed in detail, using some specific indicators, while also taking into account the role of biomarkers and lifestyle, as also suggested in another study. ${ }^{53}$

\section{Conclusion}

We can conclude that cognitive training showed a positive effect on some outcomes immediately after the intervention. Learning new strategies for using memory and cognitive functions represents a benefit for the elderly, in particular for increasing personal self-esteem and reducing psychological diseases. This could allow them to improve well-being and quality of life to live independently for a longer period.

The positive impact of the effects of cognitive training on prevention and interventions for dementia and cognitive decline could permit options that use a nonpharmacological approach to reduce the costs of related diseases of elderly subjects with dementia, as well as costs to their caregivers, which, ultimately, would have a positive impact on the National Health Service. In this context, the multidimensional assessment could represent an important instrument in terms of secondary prevention of symptoms and diseases related to cognition, including an increase of quality of life in the elderly.

$\mathrm{HE}$, as well as subjects at high risk of developing dementia, such as MCI elderly, could be treated preliminarily with this technique to slow or prevent the rate of conversion to cognitive decline and dementia. Cognitively $\mathrm{HE}$ individuals could learn some mnemonic strategies that would allow for some improvement in cognitive performance, such as memory. The multidisciplinary approach is useful for determining the best way to provide optimal management of cognitive decline, and the findings of this study could provide both health professionals and elderly people with knowledge of aspects related to cognitive decline. A recent review indicated that the development of multidomain interventions in dementia and cognitive decline, which include the study of biomarkers and lifestyle effects, is necessary. ${ }^{53}$ Further analysis regarding the role of lifestyle factors and biomarkers involved in the onset of cognitive decline could permit the identification of aspects related to cognitive decline and dementia to determine some specific health programs that are aimed at preventing cognitive diseases.

\section{Acknowledgments}

The "Ricerca Finalizzata" supported this work, which the Italian Ministry of Health and the Marche Region funded (grant number 154/GR-2009-1584108). The authors thank all of the participants and their families for their willingness to take part in this study. The authors also thank Dr. Cristina Paoloni, Dr. Mirko Pensieri, and Dr. Elisa Romanelli for their support with data collection and scientific activities.

\section{Author Disclosure Statement}

No competing financial interests exist.

\section{References}

1. Kirova AM, Bays RB, Lagalwar S. Working memory and executive function decline across normal aging, mild cognitive impairment, and Alzheimer's disease. Biomed Res Int 2015;2015:748212.

2. Irish M, Lawlor BA, Coen RF, O'Mara SM. Everyday episodic memory in amnestic mild cognitive impairment: A preliminary investigation. BMC Neurosci 2011;12:80.

3. Huey ED, Manly JJ, Tang MX, Schupf N, Brickman AM, Manoochehri M, Mez J, DeCarli C, Devanand DP, Mayeux R. Course and etiology of dysexecutive MCI in a community sample. Alzheimers Dement 2013;9:632639. 
4. Stern Y. Cognitive reserve in ageing and Alzheimer's disease. Lancet Neurol 2012;11:1006-1012.

5. Williams K, Kemper S. Exploring interventions to reduce cognitive decline in aging. J Psychosoc Nurs Ment Health Serv 2010;48:42-51.

6. Mowszowski L, Batchelor J, Naismith SL. Early intervention for cognitive decline: Can cognitive training be used as a selective prevention technique? Int Psychogeriatr 2010; 22:537-548.

7. Gates N, Sachdev PS, Fiatarone Singh MA, Valenzuela M. Cognitive and memory training in adults at risk of dementia: A systematic review. BMC Geriatr 2011;11:55.

8. Clarkson P, Giebel CM, Larbey M, Roe B, Challis D, Hughes J, Jolley D, Poland F, Russell I. Members of the HoSt-D (Home Support in Dementia) Programme Management Group. A protocol for a systematic review of effective home support to people with dementia and their carers: Components and impacts. J Adv Nurs 2015;72:186196.

9. Rodakowski J, Saghafi E, Butters MA, Skidmore ER. Nonpharmacological interventions for adults with mild cognitive impairment and early stage dementia: An updated scoping review. Mol Aspects Med 2015;43-44:38-53.

10. Ballesteros S, Kraft E, Santana S, Tziraki C. Maintaining older brain functionality: A targeted review. Neurosci Biobehav Rev 2015;55:453-477.

11. Bahar-Fuchs A, Clare L, Woods B. Cognitive training and cognitive rehabilitation for mild to moderate Alzheimer's disease and vascular dementia. Cochrane Database Syst Rev 2013;5:6.

12. Huckans M, Hutson L, Twamley E, Jak A, Kaye J, Storzbach D. Efficacy of cognitive rehabilitation therapies for mild cognitive impairment (MCI) in older adults: Working toward a theoretical model and evidence-based interventions. Neuropsychol Rev 2013;23:63-80.

13. Mowszowski L, Hermens DF, Diamond K, Norrie L, Cockayne N, Ward PB, Hickie IB, Lewis SJ, Batchelor J, Naismith SL. Cognitive training enhances pre-attentive neurophysiological responses in older adults 'at risk' of dementia. J Alzheimers Dis 2014;41:1095-1108.

14. Erickson KI, Voss MW, Prakash RS, Basak C, Szabo A, Chaddock L, Kim JS, Heo S, Alves H, White SM, Wojcicki TR, Mailey E, Vieira VJ, Martin SA, Pence BD, Woods JA, McAuley E, Kramer AF. Exercise training increases size of hippocampus and improves memory. Proc Natl Acad Sci U S A 2011;108:3017-3022.

15. Bherer L. Cognitive plasticity in older adults: Effects of cognitive training and physical exercise. Ann N Y Acad Sci 2015;1337:1-6.

16. Rebok GW, Ball K, Guey LT, Jones RN, Kim HY, King JW, Marsiske M, Morris JN, Tennstedt SL, Unverzagt FW, Willis SL, for the ACTIVE Study Group. Ten-Year effects of the advanced cognitive training for independent and vital elderly cognitive training trial on cognition and everyday functioning in older adults. JAGS 2014;62:16-24.

17. Rahe J, Petrelli A, Kaesberg S, Fink GR, Kessler J, Kalbe E. Effects of cognitive training with additional physical activity compared to pure cognitive training in healthy older adults. Clin Interv Aging 2015;10:297-310.

18. Cloninger CR. Evolution of human brain functions: The functional structure of human consciousness. Aust N Z J Psychiatry 2009;43:994-1006.

19. Boker SM. Selection, optimization, compensation, and equilibrium dynamics. GeroPsych 2013;26:61-73.
20. Kelly ME, Loughrey D, Lawlor BA, Robertson IH, Walsh $\mathrm{C}$, Brennan S. The impact of exercise on the cognitive functioning of healthy older adults: A systematic review and meta-analysis. Ageing Res Rev 2014;16:12-31.

21. Langlois F, Vu TTM, Chassé K, Dupuis G, Kergoat MJ, Bherer L. Benefits of physical exercise training on cognition and quality of life in frail older adults. J Gerontol B Psychol Sci Soc Sci 2013;68:400-404.

22. West RL, Bagwell DK, Dark-Freudeman A. Self-efficacy and memory aging: The impact of a memory intervention based on self-efficacy. Neuropsychol Dev Cogn B Aging Neuropsychol Cogn 2008;15:302-329.

23. Carretti B, Borella E, Zavagnin M, De Beni R. Impact of metacognition and motivation on the efficacy of strategic memory training in older adults: Analysis of specific, transfer and maintenance effects. Arch Gerontol Geriatr 2011;52:e192-e197.

24. Yates JA, Clare L, Woods RT. MRC CFAS. Subjective memory complaints, mood and MCI: A follow-up study. Aging Ment Health 2015;2:1-9.

25. Casoli T, Giuli C, Balietti M, Giorgetti B, Solazzi M, Fattoretti P. Effect of cognitive training on the expression of brain-derived neurotrophic factor in lymphocytes of mild cognitive impairment patients. Rejuvenation Res 2014;17: 235-238.

26. Petersen RC, Smith GE, Waring SC, Ivnik RJ, Tangalos EG, Kokmen E. Mild cognitive impairment: Clinical characterization and outcome. Arch Neurol 1999;56:303308.

27. McKhann G, Drachman D, Folstein M, Katzman R, Price D, Stadlan EM. Clinical diagnosis of Alzheimer's disease: Report of the NINCDS-ADRDA Work Group under the auspices of department of health and human services task force on Alzheimer's disease. Neurology 1984;4:939-944.

28. De Beni R, Borella E, Marigo C, Rubini E. Lab-I Empowerment Cognitivo. Firenze: Giunti Organizzazioni Speciali, 2008.

29. Alves J, Magalhaes R, Thomas RE, Goncalves OF, Petrosyan A, Sampaio A. Is there evidence for cognitive intervention in Alzheimer disease? A systematic review of efficacy, feasibility, and cost-effectiveness. Alzheimer Dis Assoc Disord 2013;27:195-203.

30. Folstein MF, Folstein SE, McHugh PR. Mini-mental state: A practical method for grading the cognitive state of patients for the clinician. J Psychiatr Res 1975;12:189-198.

31. Orsini A, Grossi D, Capitani E, Laiacona M, Papagno C, Vallar G. Verbal and spatial immediate memory span: Normative data from 1355 adults and 1112 children. Ital J Neurol Sci 1987;8:539-548.

32. Wechsler D. A standardized memory scale for clinical use. J Psychol 1945;19:87-95.

33. Borella E, Carretti B, De Beni R. Accertamento Cognitivo Negli Adulti (AMA). Firenze: Organizzazioni Speciali, 2008.

34. Spinnler H, Tognoni G. Standardizzazione e taratura italiana di test neuropsicologici. Ital J Neurol Sci 1987;6:1120.

35. De Renzi E, Faglioni P, Ruggerini C. Prove di memoria verbale di impiego clinico per la diagnosi di amnesia. Arch Psicol Neurol Psichiatr 1977;38:303-318.

36. Novelli G, Papagno C, Capitani E, Laiacona M, Cappa SF, Vallar G. Tre test clinici di memoria a lungo termine. Arch Psicol Neurol Psichiatr 1986;47:278-296. 
37. Rosen WG, Mohs RC, Davis KL. A new rating scale for Alzheimer's disease. Am J Psychiatry 1984;141:13561364.

38. Hughes CP, Berg L, Danziger WL, Coben LA, Martin RL. A new clinical scale for the staging of dementia. $\mathrm{Br}$ J Psychiatry 1982;140:566-572.

39. Yesavage JA, Brink TL, Rose TL, Lum O, Huang V, Adey $\mathrm{M}$, Leirer VO. Development and validation of a geriatric depression screening scale: A preliminary report. J Psychiatr Res 1983;17:37-49.

40. Cohen S, Kamarck T, Mermelstein R. A global measure of perceived stress. J Health Soc Behav 1983;24:385-396.

41. Katz S, Ford AB, Moskowitz RW, Jackson BA, Jaffe MW. Studies of illness in the aged. The index of ADL: A standardized measure of biological and psychosocial function. JAMA 1963;185:914-919.

42. Lawton MP, Brody EM. Assessment of older people: Selfmaintaining instrumental activities of daily living. Gerontologist 1969;9:179-186.

43. Crook TH, Feher EP, Larrabee GJ. Assessment of memory complaint in age-associated memory impairment: The MAC-Q. Int Psychogeriatr 1992;4:165-176.

44. Choi J, Twamley EW. Cognitive rehabilitation therapies for Alzheimer's disease: A review of methods to improve treatment engagement and self-efficacy. Neuropsychol Rev 2013;23:48-62.

45. Buschert VC, Friese U, Teipel SJ, Schneider P, Merensky W, Rujescu D, Moller HJ, Hampel H, Buerger K. Effects of a newly developed cognitive intervention in amnestic mild cognitive impairment and mild Alzheimer's disease: A pilot study. J Alzheimers Dis 2011;25:679-694.

46. Balash Y, Mordechovich M, Shabtai H, Merims D, Giladi N. Subjective memory decline in healthy communitydwelling elders. What does this complain mean? Acta Neurol Scand 2010;121:194-197.

47. Castro-Lionard K, Thomas-Antérion C, Crawford-Achour E, Rouch I, Trombert-Paviot B, Barthélémy JC, Laurent B, Roche F, Gonthier R. Can maintaining cognitive function at 65 years old predict successful ageing 6 years later? The PROOF study. Age Ageing 2011;40:259-265.
48. Maki Y, Yamaguchi T, Yamagami T, Murai T, Hachisuka K, Miyamae F, Ito K, Awata S, Ura C, Takahashi R, Yamaguchi $\mathrm{H}$. The impact of subjective memory complaints on quality of life in community-dwelling older adults. Psychogeriatrics 2014;14:175-181.

49. Yates JA, Clare L, Woods RT, Matthews FE. Subjective memory complaints are involved in the relationship between mood and mild cognitive impairment. J Alzheimer Dis 2015;48:S115-S123.

50. Reijnders J, van Heugten C, van Boxtel M. Cognitive interventions in healthy older adults and people with mild cognitive impairment: A systematic review. Ageing Res Rev 2013;12:263-275.

51. Valenzuela M, Sachdev P. Can cognitive exercise prevent the onset of dementia? Systematic review of randomized clinical trials with longitudinal follow-up. Am J Geriatr Psychiatry 2009;17:179-187.

52. Cooper R, Huisman M, Kuh D, Deeg DJH. Do positive psychological characteristics modify the associations of physical performance with functional decline and institutionalization? Findings from the longitudinal aging study Amsterdam. J Gerontol B Psychol Sci Soc Sci 2011; 66:468-477.

53. Andrieu S, Coley N, Lovestone S, Aisen PS, Vellas B. Prevention of sporadic Alzheimer's disease: Lesson learned from clinical trials and future directions. Lancet Neurol 2015;14:926-944.

Address correspondence to: Cinzia Giuli

Unit of Geriatrics

INRCA IRCCS

Contrada Mossa Fermo 63900

Italy

E-mail: c.giuli@inrca.it

Received: November 2, 2015 Accepted: March 7, 2016 